\title{
Perfuração de septo nasal em paciente com pioderma gangrenoso
}

\author{
Nasal septum perforation in patient with pyoderma gangrenosum \\ Camilla Bezerra da Cruz Maia', Felippe Felix², Vania Paes ${ }^{3}$, Julia Alves de Azevedo ${ }^{4}$, Eliza Raquel Negrão Grangeiro ${ }^{5}$, \\ Jonatah Lucas N. Riccio4, Helen Cruz Rito4.
}

1) Médica Residente de Otorrinolaringologia.

2) Mestre pela UFRJ. Médico do Departamento de Otorrinolaringologia do Hospital Servidor Estadual, Ministério da Saúde, Rio de Janeiro.

3) Médica Preceptora do Hospital do Servidor Estadual.

4) Médico (a) Residente de Otorrinolaringologia do Hospital do Servidor Estadual, Ministério da Saúde, Rio de Janeiro.

5) Médica Residente de Dermatologia do Hospital do Servidor Estadual, Ministério da Saúde, Rio de Janeiro.

Instituição: Hospital dos Servidores do Estado do Rio de Janeiro.

Rio de Janeiro / RJ - Brasil.

Endereço para correspondência: Camilla Bezerra da Cruz Maia - Rua Sacadura Cabral 178 - Anexo 4 - Saúde - Rio de Janeiro / RJ - Brasil - CEP: $20221-903$ - E-mail: camillabcruz@yahoo.com.br

Artigo recebido em 3 de Fevereiro de 2010. Artigo aprovado em 29 de Outubro de 2010.

\section{RESUMO}

Introdução: A cocaína é extraída das folhas do arbusto da coca (Erythroxylon coca), podendo ser consumida de várias formas, mas o modo mais comum é pela aspiração da droga, sendo absorvida pela mucosa nasal, causando vasoconstricção, levando o seu uso crônico à perfuração de septo nasal. Pioderma gangrenoso é uma doença inflamatória rara, idiopática que se caracteriza pela presença de úlceras destrutivas principalmente em membros inferiores. Seu diagnóstico clínico é muitas vezes de exclusão.

Objetivo: Descrever a raridade de associação entre Pioderma Gangrenoso e cocaína.

Relato de Caso: E. A., 27 anos, com apresentação atípica de Pioderma Gangrenoso com perfurações de septo nasal e palato duro usuária de grande quantidade de cocaína, sendo necessário diferenciar qual patologia causou esse dano.

Comentários Finais: Além da necessidade dessa diferenciação, apenas existem três casos relatados na literatura, envolvendo o Pioderma Gangrenoso complicado com perfuração de septo nasal em usuários de cocaína.

Palavras-chave: Pioderma Gangrenoso; Septo Nasal; Diagnóstico

\section{SUMMARY}

Introduction: The cocaine is obtained from the leaves of the coca (Erythroxylon coca). It can be used in many ways, but the most common is the drug inhalation. The Cocaine also causes vasoconstriction at nasal mucous membrane and its chronic use can cause necrosis and nasal septum perforation. Pyoderma gangrenosum is an uncommon idiopathic disease characterized by ulcerations, usually observed on the legs. Its diagnosis is most common an exclusion of others diseases. So far, there is no specific treatment based on evidence by randomized controlled trials.

Objective: Describe the rare association between Pyoderma gangrenosum and cocaine.

Case Report: E. A., 27-year-old woman with destruction of nasal septum and palate who has been using a big amount of cocaine, been necessary note the difference from which disease cause de damage.

Final Comments: Also there are only three cases of Pyoderma gangrenosum complicated with nasal septum perforation in cocaine users.

Keywords: pyoderma gangrenosum, nasal septum, diagnosis. 


\section{INTRODUÇÃO}

A cocaína é um alcaloide extraído da planta do gênero Erythroxylon, arbusto cultivado em regiões andinas e amazônicas. A sua dependência é possível devidoàs suas propriedades psicoestimulantes e ação anestésica local. Sob a forma de cloridrato é administrada por diferentes vias, podendo ser aspirada e absorvida pela mucosa nasal o que causa vasoconstricção de arteríolas nasais, levando a necrose e perfuração do septo nasal com o uso prolongado.

Já o Pioderma Gangrenıso é uma dermatose rara, crônica, pertencente ao espectro das dermatoses neutrofílicas, que são processos inflamatórios reativos (1). Por ser uma doença rara, reconhecida individualmente apenas no século XX por Brunsting et al. (2), a sua incidência é difícil de determinar, já que os casos publicados são geralmente isolados ou com pequeno número de doentes (3). Geralmente as lesões são múltiplas e a pele dos membros inferiores são o local mais atingido. Em 50 a 70\% dos pacientes, associa-se a uma doença de base, como doença inflamatória intestinal, doença reumática, hematológica ou malignidade (3,4). No entanto, a associação de Pioderma com cocaína, como neste caso clínico, foi descrita em apenas três relatos de caso na literatura.

O caso a ser relatado trata-se de uma paciente com Pioderma Gangrenoso diagnosticado após exclusão das demais doenças auto-imunes, porém a sua forma de apresentação é atípica e rara tanto devido ao acometimento da face quanto ao uso de cocaína associadoà patologia de base .

\section{Relato do Caso}

E. A., 27 anos, sexo feminino, parda, divorciada, do lar, natural e procedente do Rio de Janeiro, apresentando a 5 anos úlcera em hemiface esquerda que evoluiu para membros inferiores, palato duro e destruição completa do septo nasal. Afirma ser usuária de grande quantidade de cocaína por 10 anos.

No exame físico, apresentava face com úlcera de bordos mal delimitados e base eritematosa com induto purulento com algumas áreas de bordos epitelizados, ocupando, praticamente, toda a hemiface esquerda. E em membros inferiores, lesão ulcerada em perna direita. Já no exame otorrinolaringoscópico, havia na rinoscopia anterior destruição de todo septo nasal sem áreas de processo inflamatório e na oroscopia perfuração de palato duro. A otoscopia estava normal. Fez-se a endoscopia nasal visualizando perfuração septal ampla, mucosa íntegra sem aspecto de infecção ativa e presença de resíduos de muco (Figuras 1 a 6 ).

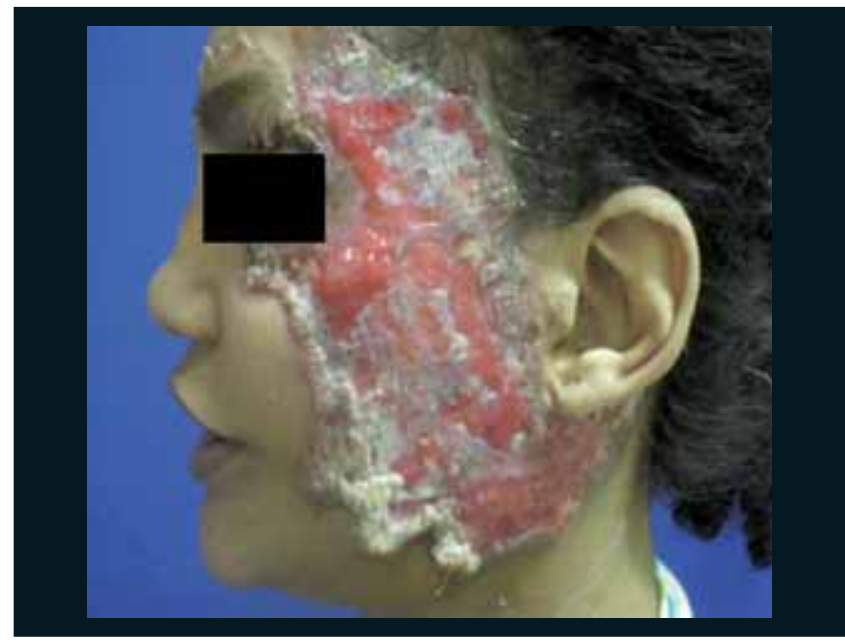

Figura 1. Úlcera de face antes do tratamento.

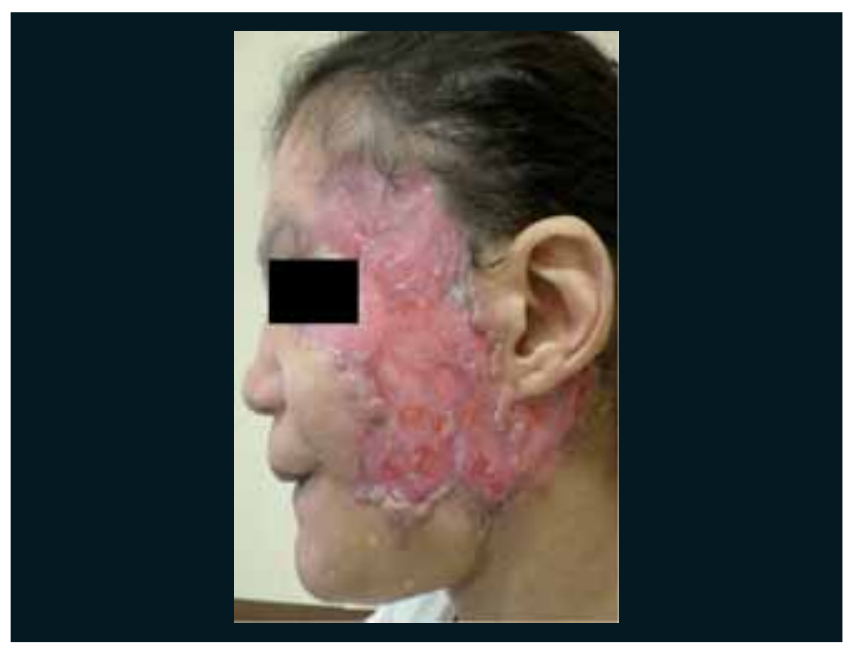

Figura 2. Úlcera de face após tratamento.

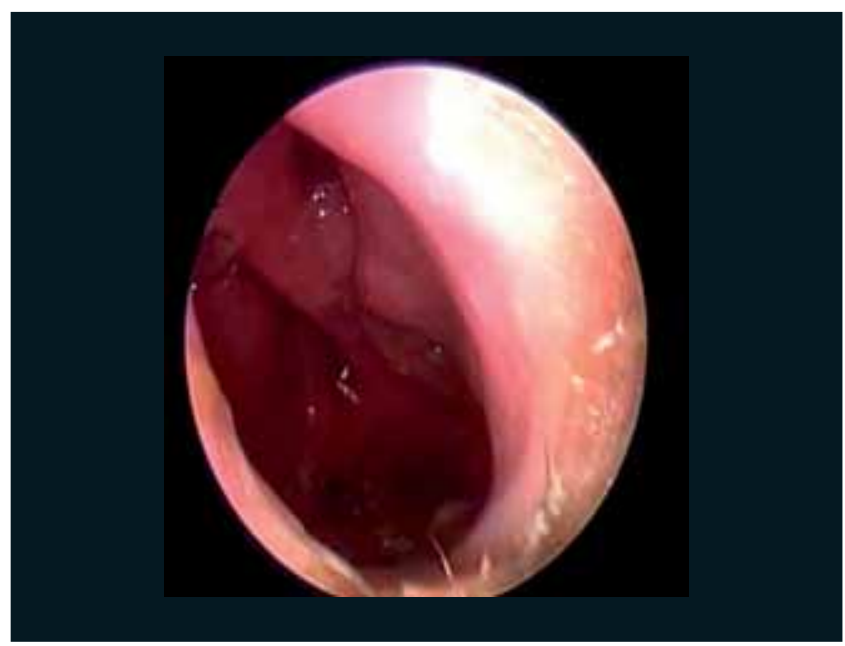

Figura 3. Perfuração de septo nasal (1). 


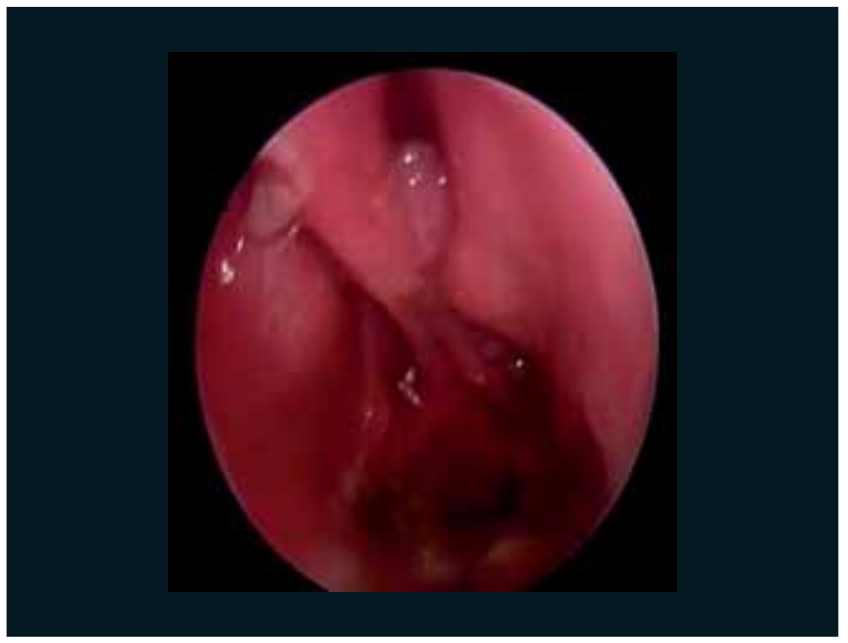

Figura 4. Perfuração de septo nasal (2).

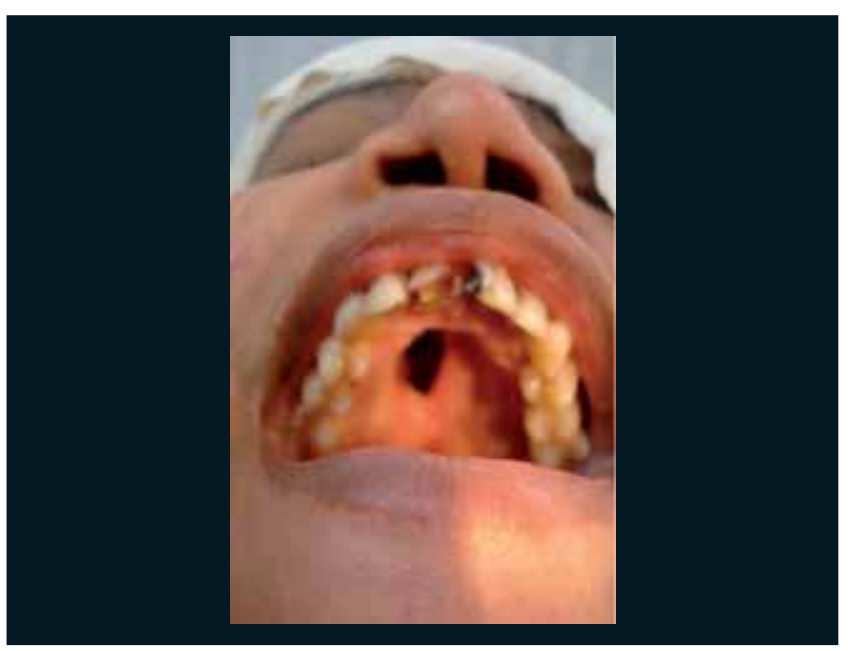

Figura 5. Perfuração de palato duro.

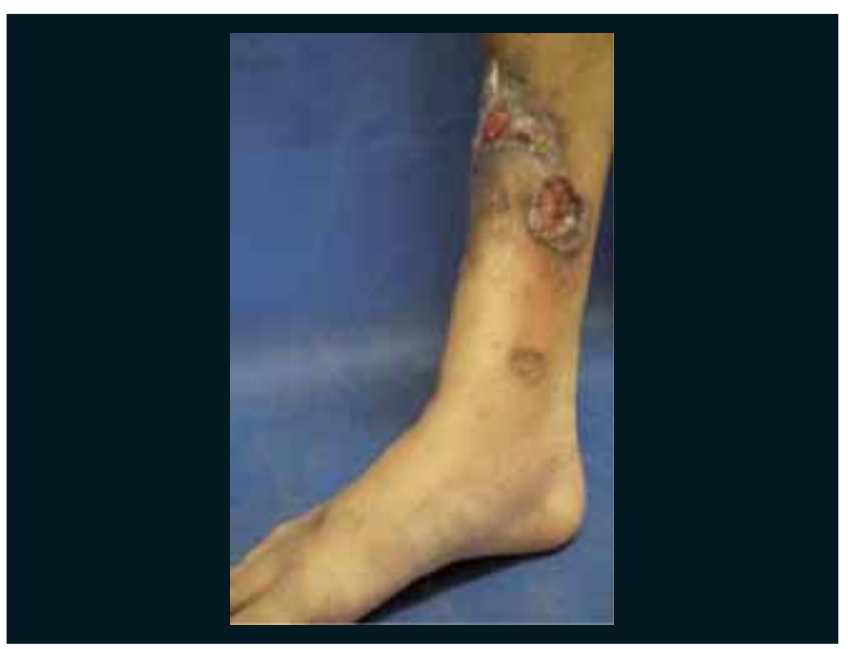

Figura 6. Úlcera de perna direita.
Nos exames laboratoriais, não evidenciou doença sintêmica associada. Anti-HTLV1 e 2 negativos; Ac anti DNA, anti-RNP, C3, C4, FAN, Anti-Ro, Anti-cardiolipina IgM e IgG, PCR e FR dentro dos valores normais; PPD: 4mm. Fez-se swab de lesão ulcerada de pele, tendo como resultado $S$. Aures. Biópsia de pele da face, sendo sugestivo de Pioderma Gangrenoso e de fragmento de mucosa de palato duro: processo inflamatório crônico ulcerado com necrose.

No tratamento, foi realizado o uso de analgésicos para dor. Vidisic gel em olho esquerdo, já que ficava sem lubrificação devido à extensa lesão. Curativo com sulfadiazina de prata em face. Azatioprina $50 \mathrm{mg}$ ao dia e Prednisona $45 \mathrm{mg}$ ao dia. Uso de prótese dentária para oclusão de perfuração palatina e transplante de córnea em olho esquerdo.

\section{DISCUSSÃO}

O pioderma gangrenoso é doença neutrofílica rara, de etiologia incerta e que se associa a doenças sistêmicas em 50\% dos casos como doença inflamatória intestinal, doença reumática, hematológica ou malignidade. É uma doença inflamatória que acomete principalmente a pele e caracteriza-se pela presença de úlceras dolorosas, destrutivas e que se expandem centrifugamente, acometendo mais frequentemente os membros inferiores. Nesta paciente, havia a presença de lesões típicas (Figura 6) e atípicas (Figura 1). O diagnóstico de pioderma gangrenoso é de exclusão, baseando-se na clínica. Os exames laboratoriais são inespecíficos, e, na maioria das vezes, apenas a velocidade de hemossedimentação está aumentada. O exame histopatológico também não é específico e apresenta aspectos variáveis dependendo do sítio da biópsia e da duração da doença, mas é fundamental para excluir outros diagnósticos (micoses profundas, úlceras vasculares, picadas de insetos, neoplasias e vasculites). Como nesse caso apresentado existia um quadro atípico com envolvimento de face e história prévia de uso de cocaína em grande quantidade, houve necessidade de diferenciar a doença de base com o uso de drogas no histopatológico, o que nos ajudou no diagnóstico final. Além disso, há apenas três casos descritos na literatura de associação entre Pioderma e cocaína considerando, assim, maior raridade do caso. Um dos reatos foi na EWMA, do Departamento de Dermatologia em Essen na Alemanha em 2009 sobre um paciente do sexo masculino usuário de grande quantidade de cocaína há 10 anos e sugerindo esse fato como causa do início do Pioderma. Já a outra publicação, em 2008, do Departamento de Dermatologia do Hospital General Universitário de Valencia na Espanha, relata dois casos de usuários de cocaína de 30 e 37 anos que também desenvolveram o Pioderma. 
Até o momento, o tratamento do pioderma gangrenoso é controverso e não há protocolos estabelecidos e adotados. As opções são diferentes esquemas de antibióticos de amplo espectro, corticosteroides, imunossupressores e imunomoduladores. Sabe-se que a instituição precoce de tratamento agressivo é capaz de diminuir a dor e prevenir cicatrizes extensas. Neste caso, optou-se pelo uso de imunossupressor associado a corticosteroide, obtendo-se resultado satisfatório com cicatrização parcial da lesão da face, pois era bastante extensa, e melhora do estado geral da paciente. Os cuidados de suporte bem como cuidados locais são importantes na prevenção de complicações e infecções secundárias como o uso de sulfadiazina de prata. Como houve comprometimento de face e dificuldade de oclusão ocular, resultou em úlcera de córnea e posterior transplante o que obteve sucesso. Na perfuração palatina, foi feito uma prótese dentária para melhora da deglutição. Já a perfuração septal apenas realiza-se acompanhamento, já que a paciente persiste no uso de drogas inaláveis.

\section{CONCLUSÃO}

O Pioderma Gangrenosoé uma doença inflamatória rara, sendo necessário excluir outras patologias para o seu diagnóstico. Como foi um caso atípico, envolvendo a face, já que esta doença acomete, geralmente, membros inferiores, houve necessidade de diferenciar se as lesões nasal e oral seriam por agressão química ou pela doença de base. Além disso, sua associação com cocaína é pouco descrita, já que só há dois casos na literatura.

\section{REFERÊNCIAS BIBLIOGRÁFICAS}

1. Brunsting La, Goeckermann, O'Leary. Pyoderma (echthyma) gangrenosum: clinical and experimental observations in five cases occurring in adults. Arch Dermatol. 1930, 22:655-680.

2. Benett ML, Jackson JM, Jorizzo JL, Fleischer ABJr, White WL, Callen JP. Pyoderma gangrenosum: a comparison of typical and atypical forms with an emphasis on time to remission. Case review of 86 patients from 2 institutions. Medicine (Baltimore). 2000, 79(1):37-46.

3. CallenJP, Jackson JM. Pyoderma Gangrenosum: an update. USA: Elsevier; 2007. p 787-802.

4. Costa IMC, Nogueira LSC. Pioderma Gangrenoso e Artrite Reumatóide - Relato de Caso. An Bras Dermatol. 2005, 80(1):81-2.

5. Hasselmann DO, Bens G, Tilgen W, Reichrath J. Pyoderma gangrenosum: clinical presentation and outcome in 18 cases and review of the literature. J Dtsch Dermatol Ges. 2007, 5:560-564.

6. Reichrath J, Bens G, Bonowitz A, Tilgen W. Treatment recommendations for Pyoderma gangrenosum: An evidence based review of the literature based on more than 350 patients. J Am Acad Dermatol. 2005, 53(2):273-83.

7. SL, Davis MDP. Neutrophilic Dermatoses. In: Bolognia JL, Jorizzo JL, Rapini RP. Dermatology, 2th edition, vol 1. USA: Elsevier; 2008. p. 383-386. 